The data for this study were collected from one pig herd, and the behavioural data were collected from whole litters. Recording behavioural activities in this way reduced the power of the statistical analysis because only eight litters were recorded. An approximate record of the behavioural activities was obtained by recording the litters involved continuously. The frequencies and the duration of the different activities were calculated precisely because the times at which the activities stopped and started were recorded.

The relationships observed between the behavioural activities of the piglets and the occurrence of lesions are preliminary findings, and should therefore not be extrapolated to the whole population. They are, however, biologically plausible and similar to the findings of a cross-sectional study of preweaning pigs (Mouttotou and others 1999), and they provide information on the origins of foot lesions and skin abrasions in young pigs. Evidence from this study showed that the development of skin lesions was related to the time that the skin was in contact with the floor. The increased time spent in the heated creep area also increased the likelihood of skin damage. Both skin and foot lesions developed early in a piglet's life and, as a previous study on the risk factors associated with the lesions showed (Mouttotou and others 1999), the provision of an ample amount of bedding during the first days after birth can help to prevent them. The bedding reduces the abrasiveness of concrete floors, protects the piglets' limbs from damage by heated floors, and also reduces the pressure on the weight-bearing surface of the foot.

\section{ACKNOWLEDGEMENTS}

The authors thank the Leonard Kalis Bequest/University of Bristol and RCVs Trust/Solvay Duphar Veterinary Award for assistance with funding this research, and also the farmer for his cooperation and help in the project. They would also like to thank S. J. Pope for assisting in setting up the video equipment on the farm and Dr C. Nicol and Dr M. T. Mendl for their valuable advice on the behavioural activities of piglets.

\section{References}

CHRISTISON, G. I. \& FARMER, C. (1983) Physical characteristics of perforated floors for young pigs. Canadian Agricultural Engineering 25, 75-80

CLARK, M. (1983) Biochemical aspects of piglet foot development. PhD Thesis, University of Aberdeen

GRAVÅS, L. (1979) Behavioural and physical effects of floors on piglets and sows. Applied Animal Ethology 5, 33-345

KIRKWOOD, B. R. (1988) Essentials in Medical Statistics. Oxford, Blackwell Scientific Publications

MAFF (1981) Injuries caused by flooring: a survey in Pig Health Scheme herds. Pig Veterinary Journal 8, 119-123

MOUTTOTOU, N., HATCHELL, F. M. \& GREEN, L. E. (1999) The prevalence and risk factors associated with forelimb skin abrasions and sole bruising in preweaning piglets. Preventive Veterinary Medicine 39, 231-245

PENNY, R. H.C., EDWARDS, M. J. \& MULLEY, R. (1971) Clinical observations of necrosis of the skin in suckling piglets. Australian Veterinary Journal 47, 529-537 PHILLIPS, P. A., FRASER, D. \& BUCKLEY, D. J. (1992) Stimulation tests on the effect of floor temperature on leg abrasion in piglets. American Society of Agricultural Engineers 35, 999-1003

PHILLIPS, P. A., FRASER, D. \& PAWLUCZAK, B. (1995) Effects of cushioned flooring on piglet leg injuries. American Society of Agricultural Engineers 38, 213-216

PHILLIPS, P. A. \& PAWLUCZUK, B. (1995) A floor overlay for reducing leg abrasion injuries on piglets. Canadian Agricultural Engineering 37, 231-233 SMITH, W. J. \& MITCHELL, C. D. (1976) Observations on injuries to suckled pigs confined on perforated floors with special reference to expanded metal (2073F). Pig Veterinary Journal 1, 91-104

SVENDSEN, J., OLSSON, O. \& NILSSON, C. (1979) The occurrence of leg injuries on piglets with the various treatment of the floor surface of the farrowing pen. Nordisk Veterinaer Medicin 31, 49-61
Veterinary Record (1999) $145,165-169$

T. Olivry, DrVet, $\mathrm{PhD}$, K. C. M. Savary, DrVet, K. M. Murphy, DVM, S. M. Dunston, BS, MS, Department of Companion Animal and Special Species, College of Veterinary Medicine, North Carolina State

University, 4700

Hillsborough Street, Raleigh, North Carolina 27606, USA

M. Chen, $\mathrm{PhD}$,

Department of

Dermatology,

Northwestern University

Medical School, 303 East

Chicago Avenue, Chicago,

Illinois 60611, USA

\title{
Bullous systemic lupus erythematosus (type I) in a dog
}

\author{
T. Olivry, K. C. M. Savary, K. M. Murphy, S. M. Dunston, M. Chen
}

In human patients with systemic lupus erythematosus, cutaneous subepidermal blistering can occur because of the production of antibodies specific for basement membrane antigens. This condition is referred to as bullous systemic lupus erythematosus (BSLE). A dog was diagnosed with BSLE because it fulfilled the following criteria: (i) a diagnosis of systemic lupus erythematosus by standard methods; (ii) an acquired, vesicular, erosive and ulcerative eruption; (iii) microscopical subepidermal vesicles with neutrophil-predominant inflammation at the dermo-epidermal junction; (iv) deposition of IgG at the epidermal basement membrane zone; and (v) circulating IgG autoantibodies against type VII collagen. Anti-collagen VII type l-BsLE therefore needs to be considered as a possible differential diagnosis for canine autoimmune subepidermal blistering diseases.

IN man, the vesicular and bullous lesions of systemic lupus erythematosus (SLE) can be a result of several pathogenic mechanisms (Sontheimer 1997, Yell and Wojnarowska 1997). In most patients, epidermal blistering develops after confluent hydropic vacuolation of basal keratinocytes (Sontheimer 1997). In others, the vesicles originate from extensive and widespread subepithelial dermo-epidermal separation (Sontheimer 1997, Yell and Wojnarowska 1997); this phe- nomenon defines a subclass of cutaneous lupus referred to as 'bullous SLE' (BSLE). Recent investigations suggest that BSLE may be a phenotypically distinctive although immunologically heterogenous bullous dermatosis (Gammon and Briggaman 1993). Patients with type I-BSLE have circulating autoantibodies that target various epitopes situated in the non-collagenous $\mathrm{NCl}$ amino-terminus of type VII collagen (Gammon and others 1985, Gammon and Briggaman 1993, 
Shirahama and others 1998). In type II-BSLE, basement membrane-specific autoantibodies are detectable in the skin, but not in the serum (Gammon and Briggaman 1993). A third subtype of BSLE has recently been recognised in which patients develop blistering dermatoses associated with serum autoantibodies specific for epidermal basement membrane glycoproteins other than collagen VII (Yell and others 1995, Yell and Wojnarowska 1997). People in whom circulating autoantibodies target multiple basal lamina proteins are also included as cases of type III-BSLE (Chan and others 1998).

Mucocutaneous lesions have been reported in 50 to 60 per cent of dogs diagnosed with SLE (Scott and Walton 1983, Fournel and others 1992). The dermatological signs of canine systemic lupus most often include seborrhoea, erythema, ulcerations, hyperkeratotic footpads, subcutaneous nodules and vitiliginous lesions (Scott and Walton 1983, Scott and others 1987, Fournel and others 1992). It is remarkable that there was no mention of cutaneous blistering in the series of 75 dogs with SLE described by Fournel and others (1992).

This paper describes a vesicular and ulcerative dermatosis that developed in a dog with SLE. The subepidermal vesicles developed in association with IgG autoantibodies specific for the lower epidermal basement membrane. The autoantibodies were shown to target the amino-terminus of collagen VII, a phenomenon previously reported in dogs with the autoimmune blistering disease epidermolysis bullosa acquisita (EBA) (Olivry and others 1998). The clinical, histological and immunological changes observed in the dog were very similar to, if not indistinguishable from, those of human patients with type I-BSLE.

\section{MATERIALS AND METHODS}

\section{Collection of specimens}

Serum and skin biopsy samples were obtained from a dog with cutaneous and constitutive signs (see below). Wedgeshaped skin biopsies were taken from the margin of a large erosive lesion on the lateral thorax. These biopsies were placed in neutral buffered formalin for histopathology and direct immunofluorescence testing. Punch skin biopsy samples $8 \mathrm{~mm}$ in diameter were taken from apparently normal skin in the immediate vicinity of the active lesions. These specimens were placed in optimal cutting temperature medium (OCT Tissue Tek; Baxter Diagnostics) and snap-frozen in isopentane cooled to its freezing point in liquid nitrogen. The frozen biopsies were kept at $-70^{\circ} \mathrm{C}$ until further processed.

\section{Detection of tissue-bound autoantibodies}

Tissue-fixed immunoreagents (IgG, IgA, IgM and complement C3 fraction) were detected by direct immunofluorescence testing of either frozen or paraffin-embedded skin sections, using a method described by Olivry and others (1998). Before they were stained, formalin-fixed specimens were treated with 0.1 per cent trypsin C (T-8128; Sigma) for 45 minutes at $37^{\circ} \mathrm{C}$. Samples of normal canine lip were used as a negative control, and skin from a dog with bullous pemphigoid served as a positive control (IgG isotype only).

\section{Detection of circulating autoantibodies}

The circulating autoantibodies were initially screened by a routine indirect immunofluorescence method, using a normal canine lip substrate and serial dilutions of the dog's serum. The extinction titre of basement membrane-specific antibodies was determined by using fluorescein-labelled anticanine IgG as described by Olivry and others (1998).

Additional indirect immunofluorescence studies were made with a lip substrate split with salt. This method uses a normal skin specimen in which the epidermal basement membrane has been cleaved artificially within the lamina lucida. The technique has been validated for dogs (Iwasaki and others 1997), and has been shown to be useful for differentiating bullous pemphigoid from EBA in dogs (Olivry and others 1998).

Circulating antinuclear IgG antibodies were detected by the indirect immunofluorescence method, using serial dilutions of the dog's serum and human hepatoma (Hep2) cells (Immuno Concepts Diagnostic Test Systems).

In all the indirect immunofluorescence studies, negative controls consisted of pooled serum obtained by mixing serum samples form 10 normal healthy dogs. Serum samples from dogs with bullous pemphigoid and EBA served as positive controls.

\section{Recombinant collagen VII-NC1 ELISA}

Recombinant $\mathrm{NCl}$ domain of human type VII collagen (145 $\mathrm{kDa}$ ) was used in an enzyme-linked immunosorbent assay (ELISA). This ELISA has been applied previously to confirm the target of the circulating autoantibodies in sera from human beings and dogs with EBA and/or BSLE (Chen and others 1997, Olivry and others 1998). Recent cloning of canine $\mathrm{NCl}$ has shown that its sequence is highly homologous to the human peptide, confirming the validity of using a heterospecific substrate for the NC1 ELISA (Chan and others 1997). To ensure the specificity of the ELISA method, sera from three dogs with EBA, one dog with bullous pemphigoid and three normal dogs were also treated.

\section{RESULTS}

\section{Clinical summary}

A four-year-old male castrated bichon frisé had had cutaneous lesions for two weeks. The dog had erosive and crusted lesions on the right elbow, axilla, lateral thorax (Fig 1), the concave surface of the pinna, and the left labial commissures. There were also ulcerative lesions on several of the dog's footpads. Erosions and ulcerations were also observed within the oral cavity, involving both the gingivae and tongue.

During the following days, the diagnosis of SLE was based on the recognition of the following abnormalities: intermittent febrile episodes, oral ulcerations, persistent proteinuria, Coombs' positive anaemia, thrombocytopenia, presumptive pleuritis and hepatitis, and detectable antinuclear antibodies (see below). The dog's symptoms satisfied four major and two minor criteria for canine SLE (Halliwell and Gorman 1989), and five of the criteria of the American College of Rheumatology adapted to dogs (Chabanne and others 1995).

Initial treatment with oral prednisone $(2 \mathrm{mg} / \mathrm{kg}$, twice daily for three weeks) did not result in any improvement. Since the diagnosis of type I-BSLE had been suspected at that time, dapsone was added, at a dose of $1 \mathrm{mg} / \mathrm{kg}$ three times per day. The combined prednisone-dapsone regimen lead to the

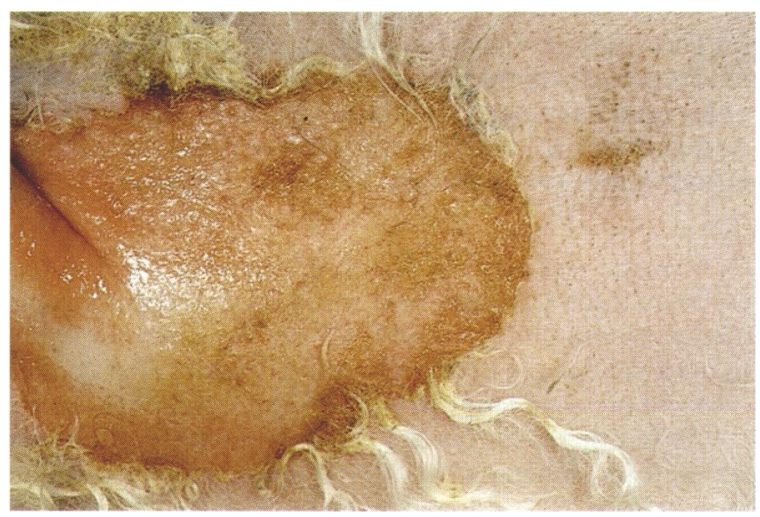


FIG 2: Early vesicles involving minimal dermal inflammation. Haematoxylin and eosin $\times 25$

FIG 4: Indirect immunofluorescence testing using normal canine lip as substrate confirming the existence of basement membrane-targeting IgG autoantibodies. $\times 200$
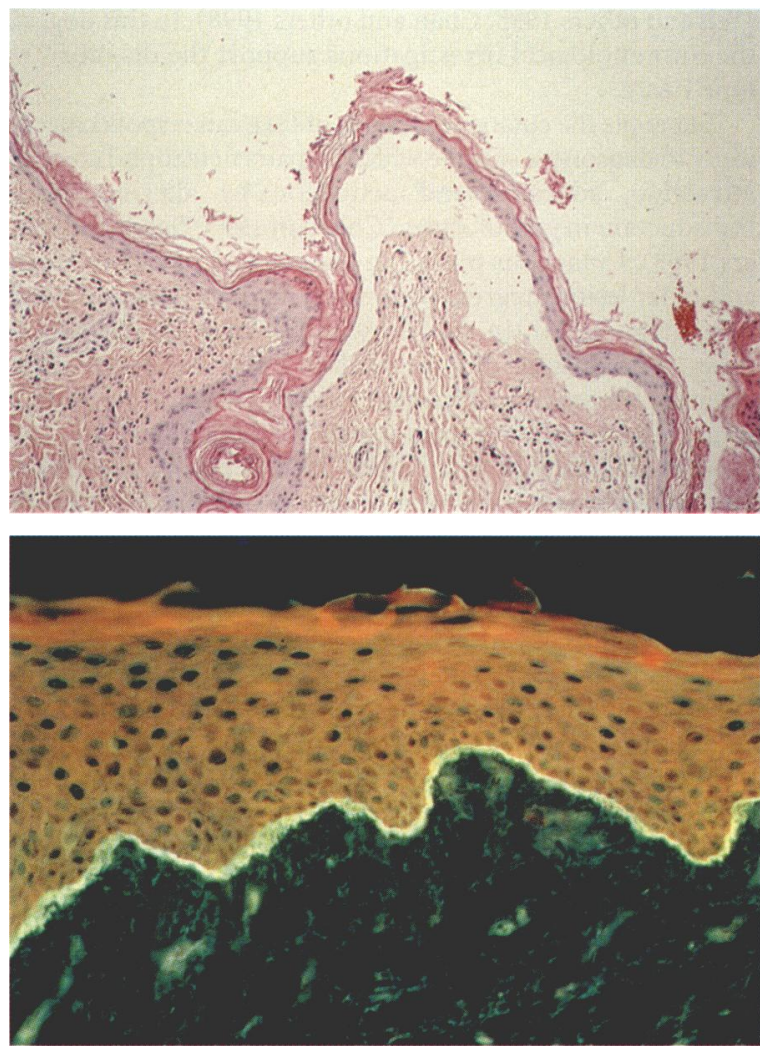

progressive amelioration of most of the cutaneous lesions and laboratory abnormalities during the following three months. The erosive lesions did not scar during the healing process. Because of an incurable recurrence of the pedal lesions, after five months of immunosuppression, the dog was euthanased at the owner's request.

\section{Histopathology}

Histopathological examination of all the specimens revealed similar findings. There was subepidermal clefting, in the absence of dermal inflammation (Fig 2), at both epidermaldermal and follicular-dermal interfaces. No vacuolation or apoptosis of basal keratinocytes was observed in areas adjacent to the vesicles. Old vesicles were filled with neutrophils and histiocytic/dendritic cells (Fig 3). Mixed inflammatory cells invaded the dermis of the developing lesions, while the epidermis overlying ageing vesicles underwent necrosis. The observed microscopical lesions were similar to those observed in the skin of dogs with EBA (Olivry and others 1998).

\section{Detection of tissue-bound autoantibodies}

Direct immunofluorescence testing of both frozen and paraffin-embedded skin biopsy specimens gave similar results. There was a linear deposition of IgG and activated complement in non-blistered areas. Whenever there was dermo-epidermal separation, the immunoreagents were co-localised at the bottom, that is, the dermal side of the vesicles. No IgA or IgM autoantibodies were detected along the basement membrane zone.

\section{Detection of circulating autoantibodies}

A very high titre $(>1: 20,000)$ of circulating IgG anti-basement membrane autoantibodies was detected in the dog's serum, using normal canine lip as substrate (Fig 4). When salt-split canine epithelium was used, the serum IgG was shown to recognise antigen(s) located on the dermal side of the clefted skin (Fig 5); these findings were identical to those observed with canine EBA serum, suggesting that the dog's antibodies

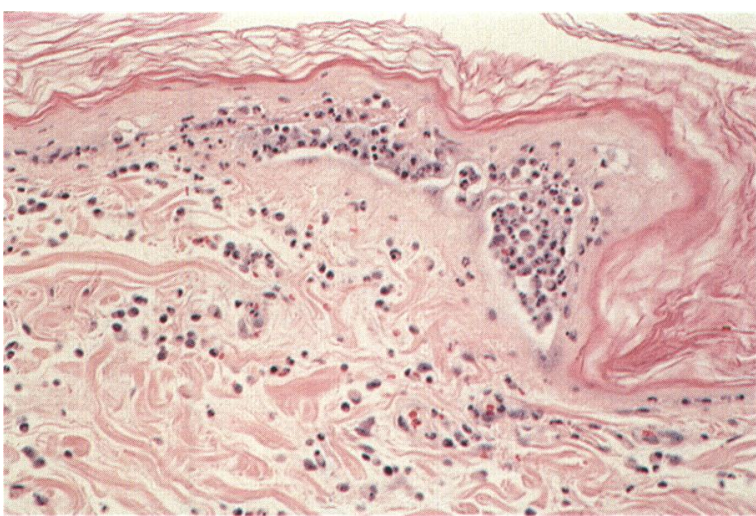

FIC 3: Polymorphic, but predominantly neutrophilic, inflammatory infiltrate in aging vesicles. Haematoxylin and eosin $\times 50$

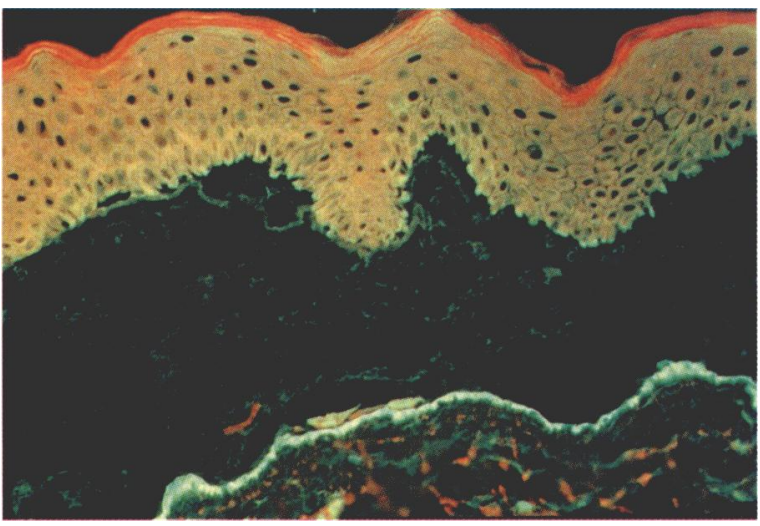

FIG 5: Indirect immunofluorescence testing, using canine saltsplit lip, showing that circulating $\lg G$ autoantibodies targeted antigen(s) located on the dermal side of the clefts. $\times 200$

might recognise collagen VII epitopes. In contrast, the canine bullous pemphigoid autoantibodies clearly labelled the epidermal side of the artificial clefts.

Antinuclear antibodies were detected in the serum with an extinction titre of 1:80. The nuclei of the human hepatoma cells had a speckled pattern of fluorescence. In the authors' laboratory a 1:80 antinuclear antibody titre, although low, was considered compatible with a diagnosis of SLE.

\section{Recombinant collagen VII-NC1-ELISA}

The dog's IgG autoantibodies were shown to bind human recombinant $\mathrm{NCl}$ domain of collagen $\mathrm{VII}$ in the heterospecific ELISA test (Fig 6). Similar binding was detected with the sera from three dogs with EBA, but not with sera from a dog with bullous pemphigoid or from normal dogs.

\section{DISCUSSION}

These results clearly demonstrate the existence in a dog of a novel acquired blistering disease that is homologous to type I-BSLE in human beings. Vesicular, erosive and ulcerative lesions, in the context of collagen VII-specific autoantibodies, therefore need to be added to the cohort of cutaneous lesions that might occur in dogs during the course of SLE.

In man, the BSLE phenotype, first described by Pedro and Dahl (1973), is characterised by a unique set of clinical, histological and immunological abnormalities (Gammon and Briggaman 1993). Human patients with BSLE have complex symptoms that meet the 1982 classification criteria of the American College of Rheumatology (formerly American 


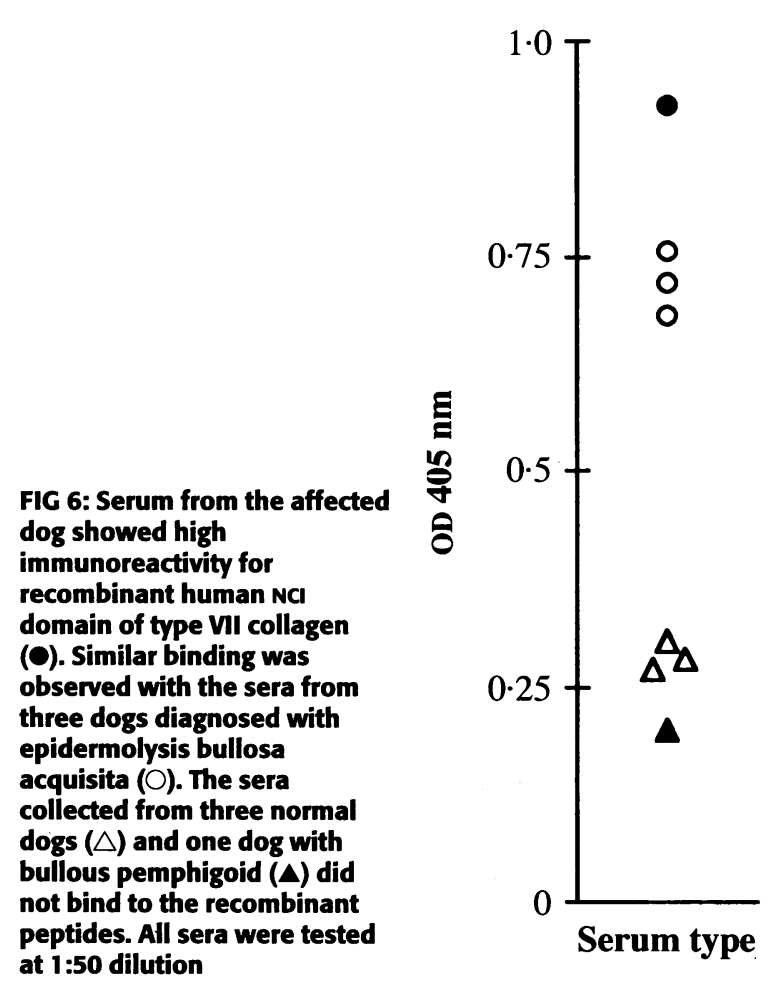

Rheumatism Association). The cutaneous lesions of BSLE appear at vesicles, bullae or erosions, and are distributed on the upper trunk and supraclavicular sites and in the oral cavity (Gammon and Briggaman 1993). The blistering lesions heal without scarring or milia, in contrast with those described in people with EBA. The severity of the cutaneous vesiculation does not necessarily coincide with an exacerbation of the systemic symptoms (Gammon and Briggaman 1993). The signs shown by this dog closely resembled the phenotype of BSLE in human beings.

Histopathological examination of skin biopsy specimens, obtained from early lesions of human patients with BSLE, reveals inflammation and dermo-epidermal separation at the level of the basement membrane (Gammon and Briggaman 1993). The inflammatory cells are predominantly neutrophil granulocytes, although some mononuclear cells and eosinophils often migrate into the blisters. Occasionally, leucocytoclastic vasculitis can be observed (Gammon and Briggaman 1993). Histological changes specific for cutaneous lupus erythematosus, that is, lymphocyte-rich interface dermatitis, are typically absent in vesicobullous lesions (Gammon and Briggaman 1993, Sontheimer 1997). In the dog, the microscopical changes in the well-developed vesicles were reminiscent of those reported in human patients with BSLE. However, early blisters were notably devoid of inflammatory cells.

Even though the clinical and histological features of BSLE in man appear remarkably homogeneous, investigations have revealed immunological heterogeneity (Gammon and Briggaman 1993, Yell and others 1995, Yell and Wojnarowska 1997). Although most human patients develop cutaneous and circulating autoantibodies directed against collagen VII (type I-BSLE), some patients develop blisters and the disposition of autoantibody is restricted to the dermal-epidermal junction (type II-BSLE) (Gammon and Briggaman 1993). Moreover, patients suffering from cutaneous blistering associated with antibodies specific for basement membrane autoantigens other than collagen VII have been reported (type III-BSLE)
(Yell and others 1995, Chan and others 1998). In this dog, all the immunological investigations support the diagnosis of type I-BSLE.

In people the cutaneous lesions of BSLE can respond specifically to dapsone, a sulfone which impairs neutrophil chemoattraction, adhesion and activation by altering signal transduction in granulocytes (Coleman 1993, Debol and others 1995). Cutaneous blistering ceases within 24 to 48 hours and older lesions regress within several days (Gammon and Briggaman 1993). In this dog, initial immunosuppressive doses of prednisone did not result in a decrease in either the extent or the severity of the skin lesions. The addition of dapsone to the treatment protocol after the diagnosis of BSLE had been made, resulted in a partial but temporary remission. Similar responses have been observed in a dog with EBA, a non-lupus-related dermatosis also associated with anti-collagen VII autoantibodies (Olivry and others 1998).

The clinical, histological and immunological changes observed in this dog meet the following criteria for type I-BSLE in human beings: (i) a diagnosis of SLE by standard criteria; (ii) an acquired, non-scarring vesicular eruption; (iii) subepidermal blisters with neutrophil-predominant inflammation at the dermo-epidermal junction; (iv) deposition of IgG at the epidermal basement membrane zone; and (v) anticollagen VII autoimmunity (Gammon and Briggaman 1993). It is therefore proposed that BSLE should be added to the expanding list of canine anti-basement membrane autoimmune dermatoses that include at least anti-collagen XVII (BP180) bullous pemphigoid (Iwasaki and others 1995) and anti-collagen VII EBA (Olivry and others 1998).

\section{ACKNOWLEDGEMENTS}

The authors are grateful to Hilary A. Jackson for editing the original manuscript.

\section{References}

CHABANNE, L., FOURNEL, C. \& MONIER, J. C. (1995) Diagnosis of systemic lupus erythematosus in dogs. Pratique Médicale et Chirurgicale de L'Animal de Compagnie 30, 115-129

CHAN, L. S., LAPIËRE, J. C., CHEN, M., MANCINI, A., PALLER, A. \& WOODLEY, D. T. (1998) Bullous systemic lupus erythematosus with IgG and IgA autoantibodies targeting multiple skin basement membrane zone components. Journal of Investigative Dermatology 110, 512A

CHAN, L. S., PENG, J., XU, L., O'TOOLE, E. A., WOODLEY, D. T. \& CHEN, M. (1997) Molecular cloning of a cDNA encoding the non-collagenous ( $\mathrm{NCl}$ ) domain of canine type VII collagen (EBA antigen). Journal of Investigative Dermatology 108, 617A

CHEN, M., CHAN, L. S., CAI, X. Y., O'TOOLE, E. A., SAMPLE, J. C. \& WOODLEY, D. T. (1997) Development of an ELISA for rapid detection of anti-type VII collagen autoantibodies in epidermolysis bullosa acquisita. Journal of Investigative Dermatology 108, 68-72

COLEMAN, M. D. (1993) Dapsone: modes of action, toxicity and possible strategies for increasing patient tolerance. British Journal of Dermatology 129, 507-513

DEBOL, S. M., HERRON, M. J. \& NELSON, R. D. (1995) Dapsone inhibits human neutrophil signal transduction induced by chemoattractants. Journal of Investigative Dermatology 104, 647 A

FOURNEL, C., CHABANNE, L, CAUX, C, FAURE, J-R, RIGAL, D, MAG NOL, J. P. \& MONIER, J. C. (1992) Canine systemic lupus erythematosus. I: a study of 75 cases. Lupus 1, 133-139

GAMMON, W. R. \& BRIGGAMAN, R. A. (1993) Bullous SLE: a phenotypically distinctive but immunologically heterogeneous bullous disorder. Journal of Investigative Dermatology 100, 28S-34S

GAMMON, W. R., WOODLEY, D. T., DOLE, K. C. \& BRIGGAMAN, R. A. (1985) Evidence that anti-basement membrane zone antibodies in bullous eruption of systemic lupus erythematosus recognise epidermolysis bullosa autoantigen. Journal of Investigative Dermatology 84, 472-476

HALLIWELL, R. E. W. \& GORMAN, N. T. (1989) Autoimmune Blood Diseases. In Veterinary Clinical Immunology. Philadelphia, W. B. Saunders Co. pp 308-335 IWASAKI, T., ISAJI, M., YANAI, T., KITAGAWA, H. \& SASAKI, Y. (1997) 
Immunomapping of basement membrane zone macromolecules in canine salt-split skin. Journal of Veterinary Medical Science 59, 391-393

IWASAKI, T., OLIVRY, T., LAPIERE, J. C., CHAN, L. S., PEAVEY, C., LIU, Y Y., JONES, J. C. R., IHRKE, P. J. \& WOODLEY, D. T. (1995) Canine bullous pemphigoid (BP) - identification of the $180 \mathrm{kD}$ canine $\mathrm{BP}$ antigen by circulating autoantibodies. Veterinary Pathology 32, 387-393

OLIVRY, T., FINE, J-D., DUNSTON, S. M., CHASSE, D., PASCAL TENORIO, A., MONTEIRO-RIVIERE, N. A., CHEN, M. \& WOODLEY, D. T. (1998) Canine epidermolysis bullosa acquisita: circulating autoantibodies target the aminoterminal noncollagenous $(\mathrm{NCl})$ domain of collagen VII in anchoring fibrils. Veterinary Dermatology 9, 19-31

PEDRO, S. D. \& DAHL, M. V. (1973) Direct immunofluorescence of bullous systemic lupus erythematosus. Archives of Dermatology 107, 118-120

SCOTT, D. W. \& WALTON, D. K. (1983) Canine lupus erythematosus. I. Systemic lupus erythematosus. Journal of the American Animal Hospital Association 19, 462-479
SCOTT, D. W., WALTON, D. K., SLATER, M. R., SMITH, C. A. \& LEWIS, R. M. (1987) Immune-mediated dermatoses in domestic animals: Ten years after - Part II. Compendium on Continuing Education for the Practicing Veterinarian 9, 539-551

SHIRAHAMA, S., FURUKAWA, F., YAGI, H., TANAKA, T., HASHIMOTO, T \& TAKIGAWA, M. (1998) Bullous systemic lupus erythematosus: Detection of antibodies against noncollagenous domain of type VII collagen. Journal of the American Academy of Dermatology 38 (Suppl 2), 844-848

SONTHEIMER, R. D. (1997) The lexicon of cutaneous lupus erythematosus - A review and personal perspective on the nomenclature and classification of the cutaneous manifestations of lupus erythematosus. Lupus 6, 84-95 YELL, J., ALLEN, J., WOJNAROWSKA, F., KIRTSCHIG, G. \& BURGE, S. (1995) Bullous systemic lupus erythematosus: revised criteria for diagnosis. British Journal of Dermatology 132, 921-928

YELL, J. A. \& WOJNAROWSKA, F. (1997) Bullous skin disease in lupus erythematosus. Lupus 6, 112-121

\section{Short Communications}

\section{Presence of 3-nitropropionic acid, in widely distributed pasture legumes in Britain}

\author{
D. J. SIMPSON, S. J. WAINWRIGHT, \\ C. R. HIPKIN
}

3-NITROPROPIONIC acid (3-NPA) is anitroaliphatic toxin which has recently been found in two common British legumes, large birdsfoot trefoil (Lotus pedunculatus) and horseshoe vetch (Hippocrepis comosa). It is toxic to both ruminants and non-ruminants (Williams and James 1975, Shenk and others 1976). The reticulorumen is the major site of absorption of 3-NPA in sheep (Pass and others 1984) where it is probably the lethal metabolite derived from the digestion of naturally occurring glucose conjugates of 3-NPA and 3nitropropanol (3-NPOH) (Majak and McDiarmid 1990). Rumen bacteria anaerobically degrade 3-NPA, forming nitrite which may be further metabolised to ammonia. Although this may cause a detoxification process in ruminants, 3-NPA and 3-NPOH poisoning in cattle after ingestion of certain Astragalus species is well documented (Williams and Barnaby 1977) and nitrite poisoning has been reported in sheep (Holtenius 1957) and cattle (Winter 1962). The symptoms of acute 3-NPA poisoning are general weakness, incoordination in the hindquarters, trembling, laboured and audible breathing, collapse and ultimately, death (Williams and James 1978). In addition, nitrite produced by the degradation of 3-NPA gives rise to methaemoglobinaemia when absorbed into the blood stream (Majak and others 1981, Muir and others 1984).

3-Nitropropionic acid is a suicide inhibitor of the mitochondrial enzyme succinate dehydrogenase (Alston and others 1977, Gould and others 1985) and depresses adenosine triphosphate (ATP) levels in rodent central nervous system tissue in vitro (Ludolph and others 1992). Chronic admin istration of 3-NPA to rats produces age dependent selective stri- atal lesions, which resemble some of the pathological changes seen in Huntington's disease, an inherited neurodegenerative disease in human beings (Wüllner and others 1994).

High concentrations of 3-NPA have been detected in leaf extracts of horseshoe vetch and large birdsfoot trefoil, the highest levels being recorded in horseshoe vetch, with values ranging from approximately 60 to $170 \mu \mathrm{mol} 3-\mathrm{NPA} / \mathrm{g}$ fresh weight of leaves. There is a seasonal variation, with higher levels of 3-NPA in horseshoe vetch from April to September (Fig 1). 3-Nitropropionic acid was found in horseshoe vetch samples from 18 sites around Britain (Fig 2), with levels of 44.5 to $154.6 \mu \mathrm{mol} 3-\mathrm{NPA} / \mathrm{g}$ fresh weight leaves. 3-NPA was also measured in field samples of large birdsfoot trefoil from six sites in south Wales, and values ranged from 7.6 to $31.7 \mu \mathrm{mol}$ $3-\mathrm{NPA} / \mathrm{g}$ fresh weight leaves.

Stock poisoning by 3-NPA and 3-NPOH is accepted in the USA as a problem associated with grazing of pastures containing Astragalus species. Available literature on poisonous plants and their effect on livestock in Britain (Cooper and Johnson 1998) also include descriptions of 3-NPA toxicity in conjunction with milk vetch (Astragalus species) and crown vetch (Coronilla varia). However, none of the milk vetch species which occur in the UK contains 3-NPA (Salem and others 1995, D. J. Simpson, C. R. Hipkin, S. J. Wainwright, unpublished

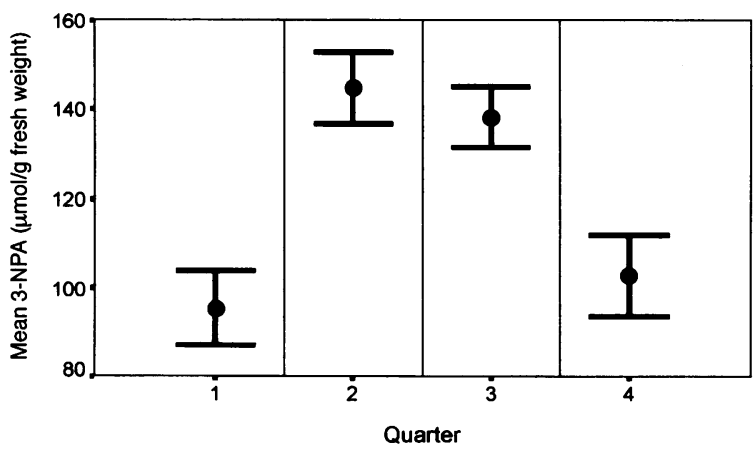

1 January to March, 2 April to June, 3 July to September, 4 October to December

FIG 1: Mean concentrations of 3-nitropropionic acid (3-NPA) in Hippocrepis comosa leaves. Error bars indicate 95 per cent confidence intervals 